Research article

\title{
Early recovery of microvascular perfusion induced by t-PA in combination with abciximab or eptifibatide during postischemic reperfusion \\ Silva Bertuglia* and Andrea Giusti
}

\author{
Address: CNR Institute of Clinical Physiology, School of Medicine, University of Pisa, 56100 Pisa, Italy \\ E-mail: Silva Bertuglia* - sibert@ifc.cnr.it; Andrea Giusti - andreagiusti1@hotmail.com \\ ${ }^{*}$ Corresponding author
}

Published: 19 June 2002

Received: 21 January 2002

BMC Cardiovascular Disorders 2002, 2:10

Accepted: 19 June 2002

This article is available from: http://www.biomedcentral.com/ |47/-226I/2/10

(C) 2002 Bertuglia and Giusti; licensee BioMed Central Ltd. Verbatim copying and redistribution of this article are permitted in any medium for any purpose, provided this notice is preserved along with the article's original URL.

\begin{abstract}
Background: GPIIb/llla inhibitors abciximab and eptifibatide have been shown to inhibit platelet aggregation in ischemic heart disease. Our aim was to test the efficacy of abiciximab (Reo Pro) or eptifibatide (Integrilin) alone or in combination with plasminogen activator (t-PA) in an experimental model of ischemia reperfusion $(I / R)$ in hamster cheek pouch microcirculation visualized by fluorescence microscopy. Hamsters were treated with saline, or abiciximab or eptifibatide or these drugs combined with t-PA infused intravenously 10 minutes before ischemia and through reperfusion. We measured the microvessel diameter changes, the arteriolar red blood cell $(R B C)$ velocity, the increase in permeability, the perfused capillary length $(P C L)$, and the platelet and leukocyte adhesion on microvessels.

Results: I/R elicited large increases in the platelet and leukocyte adhesion and a decrease in microvascular perfusion. These responses were significantly attenuated by abiciximab or eptifibatide (PCL:70 and $65 \%$ at $5-10$ mins of reperfusion and 85 and $87 \%$ at 30 mins of reperfusion, respectively, $P<0.00$ I) while t-PA combined with abiciximab or eptifibatide, was more effective and microvascular perfusion recovered immediately after postischemic reperfusion.

Conclusions: Platelets are crucial in $I / R$ injury, as shown by the treatment with abicixmab or eptifibatide, which decreased platelet aggregation in microvessels, and also decreased leukocyte adhesion in venules. Arterial vasoconstriction, decreased arterial RBC velocity and alterations in the endothelial barrier with increased permeability delayed the complete restoration of blood flow, while t-PA combined with inhibition of platelet aggregation speeded up the capillary perfusion after reperfusion.
\end{abstract}

\section{Background}

A role for platelets in the pathogenesis of $\mathrm{I} / \mathrm{R}$ is supported by reports describing a beneficial effect of platelet depletion in the no-reflow phenomenon in different experimental models of $I / R$ [1-3]. Platelets are a major constituent of newly formed thrombi and contribute sig- nificantly to vaso-occlusive disease in I/R-induced injury because the platelet-endothelial interactions are not confined to postcapillary venules but have been also observed in arterioles during $\mathrm{I} / \mathrm{R}$ [4]. 
Inhibitors of the platelet glycoprotein gpIIb/IIIa have been designed, which interfere with the ability of these receptors to bind fibrinogen and thus to form platelet aggregates. These are a chimeric monoclonal antibody (c7E3 Fab), Reo Pro or abciximab [5-9] and a cyclic heptapeptide, Integrilin or eptifibatide [10-12] containing a KGD sequence developed as a high affinity mimic of the fibrinogen RGD sequence, which binds to the gp IIb-IIIa receptor. They have been shown to be specific for inhibition of platelet aggregation (and possibly adhesion) in human ischemic heart disease $[10,13,14]$. However, there have been different studies on the effects of these compounds in vitro and in humans, but the efficacy at the level of the microvessels, which comprise this network range in size from 5 to $150 \mu \mathrm{m}$, during I/R has not been reported.

Epidemiological studies have shown complete restoration of blood flow with plasma tissue plasminogen activator (t-PA) levels but the incidence of microvascular reocclusion, caused by arterial thrombosis, is high in patients $[13,15,16]$. t-PA, released from endothelial cells, is a major activator of fibrinolysis and has a major role in platelet adhesion to damaged vessels [17]. A combination reperfusion regimen that includes abciximab and a reduced dose of a thrombolytic agent, followed by an early adjunctive percutaneous coronary intervention, was associated with greater ST-segment resolution [18]. Combined accelerated t-PA and eptifibatide in human acute myocardial infarction showed that the restoration of perfusion can be enhanced when eptifibatide is associated with other drugs such as alteplase, aspirin or intravenous heparin factors that can protect the endothelium [19]. Injury to endothelial cells may suppress production of prostacyclin and promote production of tromboxaneA2 in the vessel wall thus causing platelets to become adherent to damaged vessels.

Previously, we showed that the removal of leukocytes (leukopenia) was protective against I/R injury, only when it was in combination with t-PA treatment [20], thus showing evidence that leukocytes and t-PA play a central role in thrombosis and are involved in the fibrinolytic processes.

Although abiciximab and eptifibatide exhibit significant benefits in treating I/R injury, it is unclear whether their therapeutic properties are localized in the inhibition of platelet aggregation alone or in the protection of endothelial cells with the inhibition of leukocyte adhesion molecules and endothelium-platelet or platelet-leukocyte interactions.

The first aim of our study was to determine the efficacy of abciximab or eptifibatide to attenuate leukocyte adhesion and to restore blood flow after I/R-induced injury in the hamster cheek pouch microcirculation. The second aim was to test whether t-PA combined with gpIIb-IIIa antagonists would increase microvascular perfusion after I/R. The adherent platelets and leukocytes in microvessels, capillary perfusion (capillary segments perfused by red blood cells, perfused capillary length, PCL), increased permeability, and arteriolar and venular RBC velocity were investigated by fluorescence microscopy.

\section{Results}

MAP and heart rate were $90 \pm 7 \mathrm{~mm} \mathrm{Hg}$ and $280 \pm 10$ beats/min during baseline conditions and they did not change significantly after I/R. t-PA, abicimax and eptifibatide did not affect either MAP or heart rate significantly.

\section{Changes in arteriolar diameter and $R B C$ velocity}

The changes in the diameter of arterioles (baseline: $55 \pm 7$ $\mu \mathrm{m}, \mathrm{n}=15$ ) measured after $30 \mathrm{~min}$ of reperfusion are shown in Fig. 1. In the I/R group the diameter of arterioles decreased significantly after reperfusion compared with baseline $(-45 \%$ vs. baseline, $\mathrm{p}<0.05)$ whereas the venules dilated slightly. The values in tPA group were not significantly different compared with I/R group during baseline and reperfusion (tPA: $-36 \%$ vs. baseline, $\mathrm{p}<0.05$ ).

In $\mathrm{tAB}$ and $\mathrm{tEF}$ groups there was a significant increase in arteriolar diameter compared with $\mathrm{I} / \mathrm{R}$ whereas in the groups treated with t-Pa combined with gpIIa/IIIb inhibitors, diameters maintained or increased its baseline value at the end of the observation period (tAB: $+12 \%$ and tEF: $+15 \%$ vs. the $\mathrm{AB}$ and $\mathrm{EF}$ groups, respectively $\mathrm{p}<0.05$ ).

There was not a significant difference in baseline RBC velocity in I/R and tPA groups. Just after the ischemic period a significant decrease in RBC velocity was observed in both groups and during the subsequent period of reperfusion (1.98 $\pm 0.35 \mathrm{~mm} / \mathrm{s}$ at baseline, $\mathrm{p}<0.05)$ (Fig. 2). In $A B$ and $E F$ groups $R B C$ velocity increased significantly in arterioles during reperfusion in comparison with $\mathrm{I} / \mathrm{R}(\mathrm{p}$ $<0.05$, Figs. 1,2) whereas it further increased in either groups treated with t-PA in combination with gpIIa/IIIb inhibitors (tAB: $42 \%$ and tEF: $46 \%$ vs. the $\mathrm{AB}$ and $\mathrm{EF}$ groups, respectively, $\mathrm{p}<0.05$ ).

\section{Changes in venular permeability}

Before ischemia no detectable fluorescent dextran leakage was observed in all the groups. In the I/R and tPA groups a significant increase in permeability was observed in postcapillary and collecting venules during reperfusion (baseline: $0.09 \pm 0.01$ normalized grey levels, $\mathrm{p}<0.05$, Fig. 3). The treatment with abiciximab and eptifibatide significantly attenuated the $\mathrm{I} / \mathrm{R}$-induced increase in permeability from venules $30 \mathrm{~min}$ after reperfusion. In $\mathrm{AB}$ and $\mathrm{EF}$ groups a slight increase in permeability was observed from 20-30 min after reperfusion when compared 


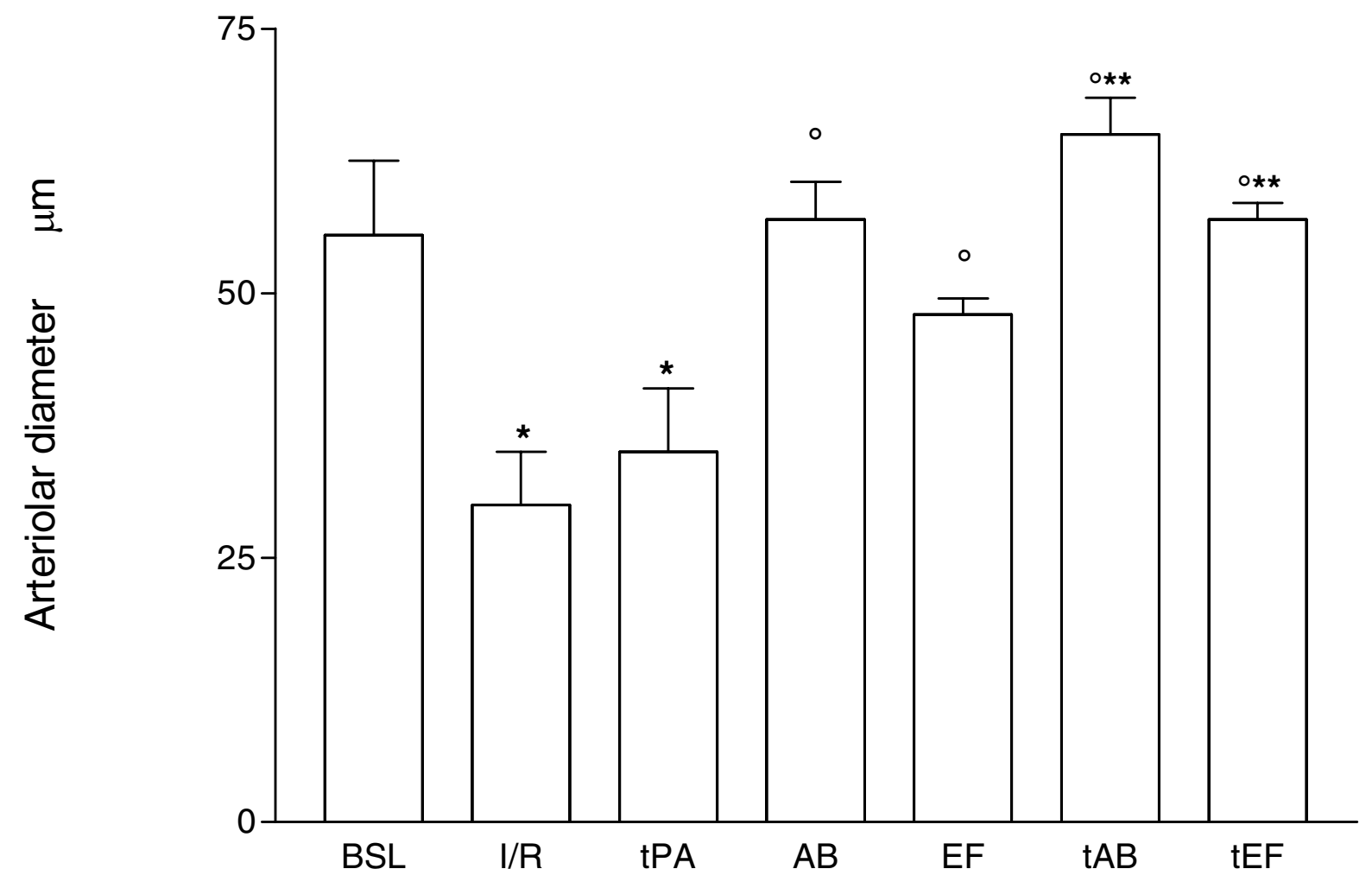

Figure I

Changes of diameter of arterioles at baseline and during reperfusion in the group treated with saline (I/R) and those treated with abiciximab $(A B)$, eptifibatide (EF), t-PA (tPA) and abiciximab plus t-PA (tAB) or eptifibatide plus t-PA (tEF), respectively. See text for details. Values are means $\pm \mathrm{SD}, \mathrm{n}=35$ experimental observations for each entry, ${ }^{*} \mathrm{P}<0.05 \mathrm{I} / \mathrm{R}$-tPA vs. baseline; ${ }^{\circ} \mathrm{P}$ $<0.05 \mathrm{AB}-\mathrm{EF}-\mathrm{tAB}-\mathrm{tEF}$ vs. I/R and tPA; ${ }^{* *} \mathrm{P}<0.05 \mathrm{tAB}$ and $\mathrm{tEF}$ vs.AB and $\mathrm{EF}$.

with $\mathrm{tEF}$ and $\mathrm{tAB}$ groups (tAB $-25 \%$ and $\mathrm{tEF}:-57 \%$ vs. the $\mathrm{ABI}$ and EF groups, respectively, $\mathrm{p}<0.05$ )

\section{Changes in platelet and leukocyte adhesion on microves-} sels

In the I/R and tPA group the number of platelets adhering to arterioles or venules and the number of leukocytes adhering to the postcapillary venules increased significantly in comparison with baseline values (Figs. 4,5).

t-PA had no protective effect on the number of adhering platelets in postischemic arterioles and venules. On the contrary t-PA combined with gpIIa/IIIb inhibitors de- creased the number of platelets adhering to arterioles and venules. Concomitantly, the number of leukocytes adhering to the postcapillary venules decreased significantly compared with I/R group (Figs. 4,5).

The number of leukocytes adhering to the venular wall decreased significantly by the end of reperfusion (Fig. 5) with abiciximab or eptifibatide alone (AB: $-42 \%$ and EF: $46 \%$ vs. the I/R group, $\mathrm{p}<0.05)$. With abiciximab and eptifibatide there was a significant reduction in platelet adhesion in microvessels (AB: -72 and EF:-74\% $\mathrm{p}<0.01$ vs. the $\mathrm{I} / \mathrm{R}$ group). In the $\mathrm{AB}$ and $\mathrm{EF}$ groups the leukocyte adhesion to venules was -46 and $-50 \%$ in comparison with 


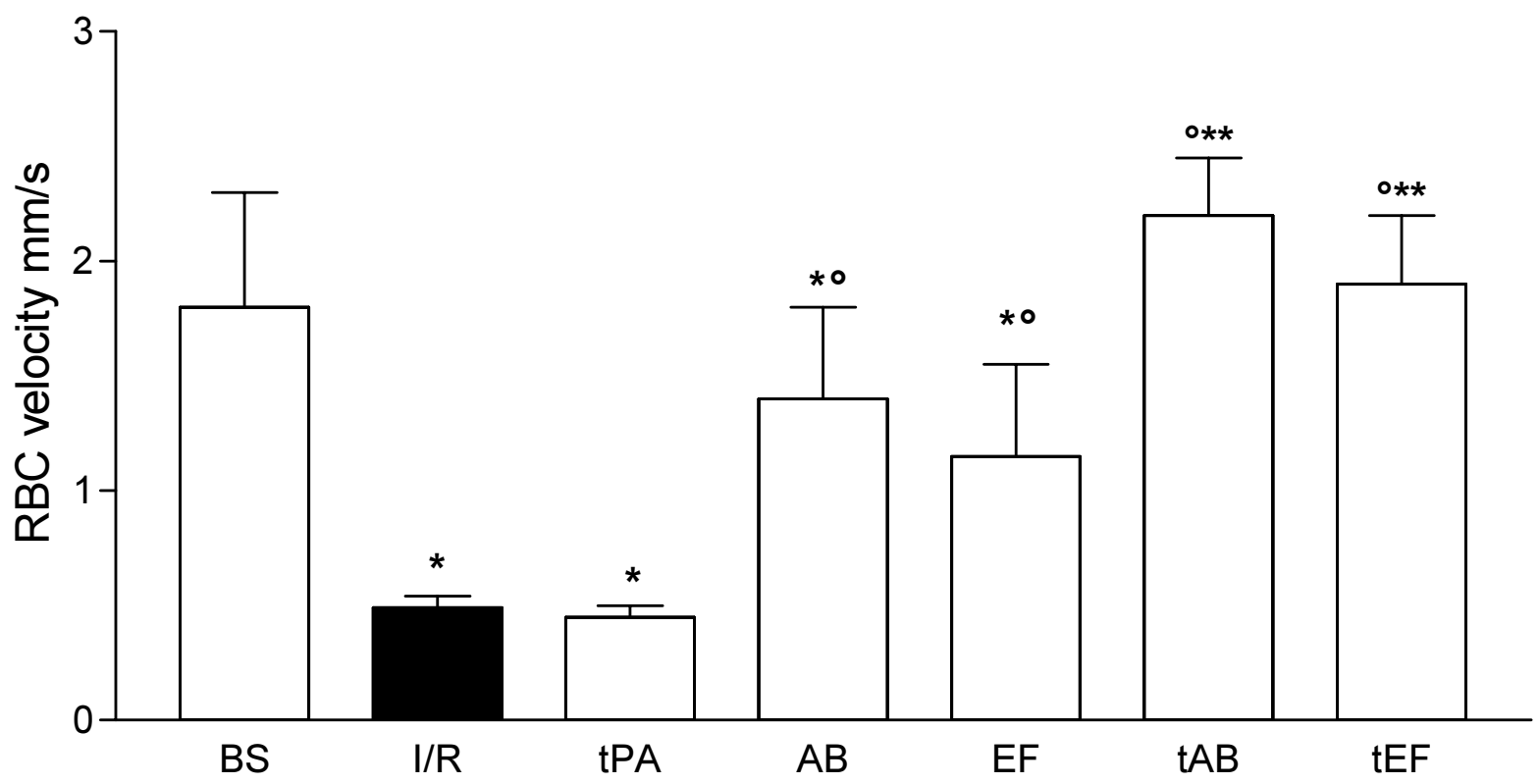

\section{Figure 2}

Changes of arteriolar RBC velocity at baseline and during reperfusion in the group treated with saline (I/R) and those treated with abiciximab (AB), eptifibatide (EF), t-PA (tPA) and abiciximab plus t-PA (tAB) or eptifibatide plus t-PA (tEF), respectively. See text for details. Values are means $\pm S D, n=20$ experimental observations for each entry, ${ }^{*} P<0.05$ I/R-tPA vs. baseline; ${ }^{\circ} P$ $<0.05 \mathrm{AB}, \mathrm{EF}, \mathrm{tAB}$, and tEF vs. I/R and tPA; ${ }^{* *} \mathrm{p}<0.05 \mathrm{tAB}$ abd tEF vs.AB and EF.

the I/R group, respectively ( $\mathrm{p}<0.001$ ) (Fig. 5). However, the number of leukocytes adhering on postcapillary venules was significantly different when compared with the $\mathrm{tEF}$ and $\mathrm{tAB}$ groups ( $\mathrm{tAB}:-37 \%$ and $\mathrm{tEF}-26 \%$ vs. the $\mathrm{AB}$ and EF groups, respectively, $\mathrm{p}<0.05)$.

\section{Changes in capillary perfusion}

In I/R group PCL decreased significantly when compared with baseline (baseline: 9,130 $\pm 430 \mu \mathrm{m}, \mathrm{p}<0.05$, Fig. 6 . In Fig. 7 and 8 we reported the photographic sequence of a hamster cheek pouch microcirculation during baseline, $30 \mathrm{~min}$ of ischemia, $10 \mathrm{~min}$ and $30 \mathrm{~min}$ of reperfusion. The no reflow phenomenon is evident during reperfusion as shown by the lack of capillary perfusion at 10 and 30 min from reperfusion. t-PA had no effect on capillary perfusion (PCL: $58 \pm 5 \%$ of baseline, $10,080 \pm 400 \mu \mathrm{m}$ ) while combination of t-PA with abiciximab and eptifibatide determined no alteration in capillary perfusion compared with the baseline (9980 $\pm 350 \mu \mathrm{m}$, Fig. 6). PCL increased significantly in comparison with the I/R group, whereas it was slightly but significantly reduced in comparison with the baseline (baseline: $\mathrm{AB}: 8,950 \pm 780 \mu \mathrm{m}$; EF: 9,780 \pm $540 \mu \mathrm{m}$ ) (Fig. 6). In the $\mathrm{AB}$ and EF groups postischemic perfusion in the microcirculation showed a biphasic increase because within 5-10 min after the onset of reperfusion, PCL was 70 and $65 \%$ and 85 and $87 \%$ after $30 \mathrm{~min}$ of reperfusion, vs. the baseline $(10,500 \pm 500 \mu \mathrm{m}, \mathrm{p}<$ $0.001)$. In Fig. 7 and 8 we reported the photographic sequence of hamster cheek pouch treated with abiciximab. The capillary perfusion recovered within 10 min after postischemic reperfusion and after 30 min there was not a complete capillary perfusion.

PCL increased significantly in the groups treated with t-PA combined with gpIIa/IIIb inhibitors in comparison with the $\mathrm{AB}$ and $\mathrm{EF}$ groups (tAB: 26 and 15\% and $\mathrm{tEF}: 31$ and $13 \%$ within 15 and 30 min of reperfusion vs. the $A B$ and EF groups, respectively, $\mathrm{p}<0.05)$. Interestingly, we did not 


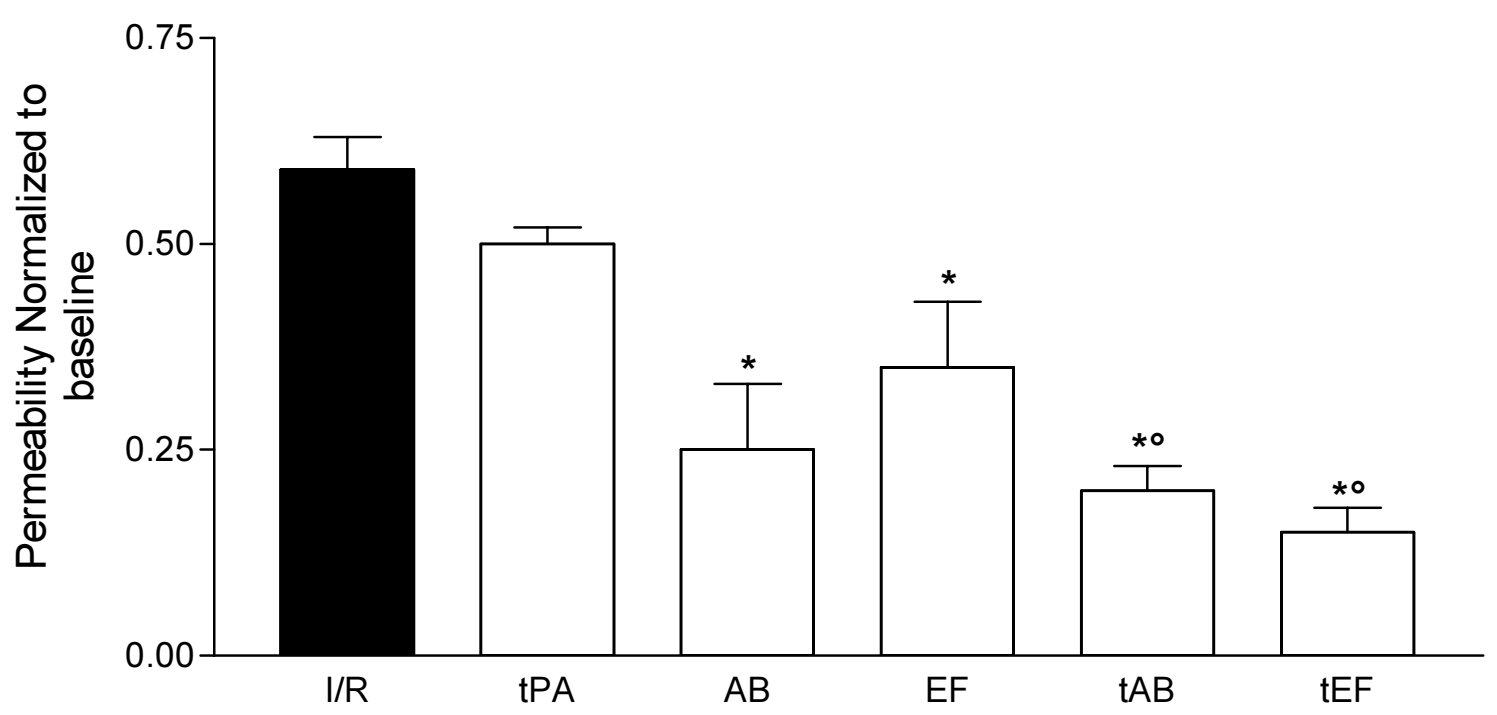

Figure 3

The permeability (normalized to baseline) during reperfusion in the group treated with saline (I/R) and those treated with abiciximab (AB), eptifibatide (EF), t-PA (tPA) and abiciximab plus t-PA (tAB) or eptifibatide plus t-PA (tEF), respectively. See text for details. Values are means $\pm S D .{ }^{*} \mathrm{P}<0.05 \mathrm{AB}, \mathrm{EF}, \mathrm{tAB}$ and $\mathrm{tEF}$ vs. $\mathrm{I} / \mathrm{R}$ and $\mathrm{t}-\mathrm{PA} ;{ }^{\circ} \mathrm{P}<0.05 \mathrm{tAB}$ and $\mathrm{tEF}$ vs.AB and $\mathrm{EF}$.

observed the postischemic biphasic response in blood flow as in $\mathrm{AB}$ and EF groups but microvascular perfusion was restored to the preclamping level immediately after the period of ischemia.

\section{Discussion}

Our data demonstrated that the inhibition of platelet aggregation is a crucial event in I/R injury in microvessels as shown by the effects derived from the treatment with abicixmab or eptifibatide in the hamster cheek pouch microcirculation. These drugs reduced platelet aggregation in arterioles and venules, as well as leukocyte adhesion to endothelial cells of venules and leukocyte-platelet interactions in microvessels. Although microvascular perfusion was maintained after 30 min of reperfusion the restoration of blood flow was only within 5-10 min after postischemic reperfusion.

t-PA combined with abcixmab or eptifibatide-mediated inhibition of platelet aggregation enhanced and speeded the restoration of the microvascular perfusion by protecting the endothelial barrier as shown by the decrease in venular permeability and the increase in arteriolar diameter. The results obtained in this model indicate that there was still a significant efficacy against microcirculatory disturbances after gpIIa/IIIb inhibitors alone with respect to their combination with t-PA. This suggest that the increased levels of platelet activation and fibrinolysis are involved more importantly than other factors in I/R injury. The early recovery of blood flow at the beginning of reperfusion may be protective for reducing cellular endothelial cell injuries.

Previously, we have reported that platelet adhesion was not confined to postcapillary venules, but was also observed in arterioles of the hamster cheek pouch microcirculation during I/R [4]. The decreased perfusion observed in the capillary network at the beginning of reperfusion might be related to the increased level of platelet reactivity in the arterioles during the period of ischemia. Protein kinase $\mathrm{C}$ (PKC) is sensitive to oxidation and could be upregulated during oxidative stress caused by ischemia. It was shown that many proaggregatory stimuli, such as oxidative stress, have activated PKC involved in the platelet ac- 


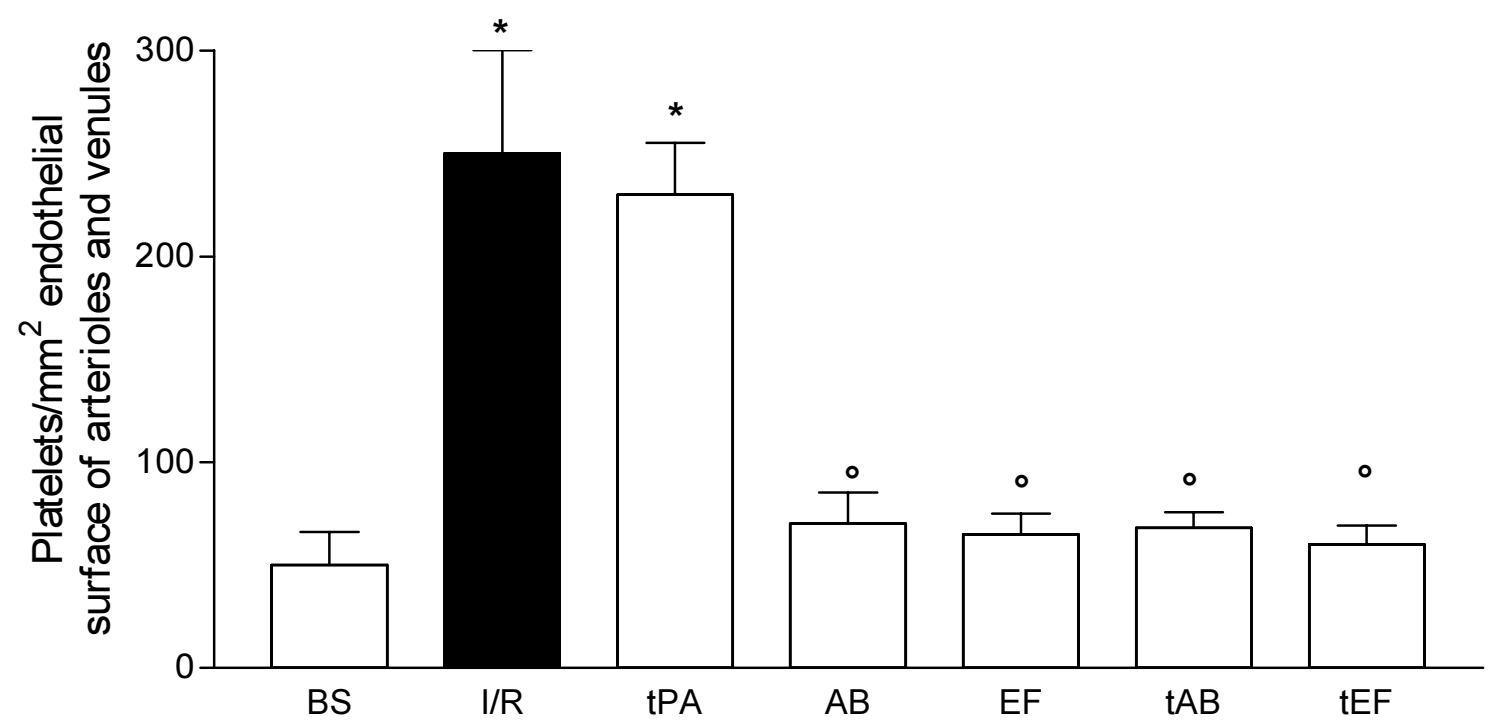

Figure 4

Number of adherent platelets/ $\mathrm{mm}^{2}$ of vessel surface at baseline and during reperfusion in the group treated with saline (I/R) and those treated with abiciximab (AB), eptifibatide (EF), t-PA (tPA) and abiciximab plus t-PA (tAB) or eptifibatide plus t-PA $(t E F)$, respectively. See text for details. Values are means $\pm S D, n=35$ experimental observations for each entry, ${ }^{*} P<0.05$ vs. baseline; ${ }^{\circ} \mathrm{P}<0.05$ vs. I/R and tPA.

tivation [21]. The increase in the oxidative stress at the onset of reperfusion could lead to an increase in P-selectin expression on the endothelial surface thus increasing platelet and leukocyte adhesion to microvessels [22,23]. In particular, endothelial cells appear to be very sensitive to an enhanced level of platelet activation after oxygen free radicals or cytokine exposure following ischemic occlusion [12]. Inflammatory markers, such as interleukin-6 and tumor necrosis factor- $\alpha$, measured in serum samples obtained from 160 patients during angioplasty, decreased significantly in the first hours after angioplasty following administration of abciximab. It was hypothesized that some of the decreased mortality associated with the use of this agent may be related to an anti-inflammatory effect exerted by abiciximab [9]. However, measurement of routine enzymes following early myocardial infarction did not reveal any early benefit provided by abiciximab [11].

In the microcirculation of hamsters after platelet aggregation inhibition we did not observe arterial vasoconstriction or significant decreases in RBC velocity after I/R but an increase in permeability was observed during reperfusion thus indicating an impairment of the endothelial barrier.

It is possible that platelets contributed in part to the delay in reperfusion through a release of vasoconstrictor substances, thus causing local perfusion deficiencies of the microcirculation with occlusion of the vascular lumen and alterations in the properties of the endothelial barrier $[4,24]$.

Platelets in the arterial circulation are exposed to very high shear stress at the beginning of reperfusion. The shear-induced platelet aggregation is enhanced in plasma in the presence of acute myocardial infarction, apparently as a result of increased concentration of von Willebrand factor (vWF) [15]. Under such conditions the time for contact with damaged vessels is very limited, and it is surprising that high shear stress favors interaction of platelets with the subendothelium. Interestingly, after a first peak of adhesion, there is a rapid decrease in the number of adher- 


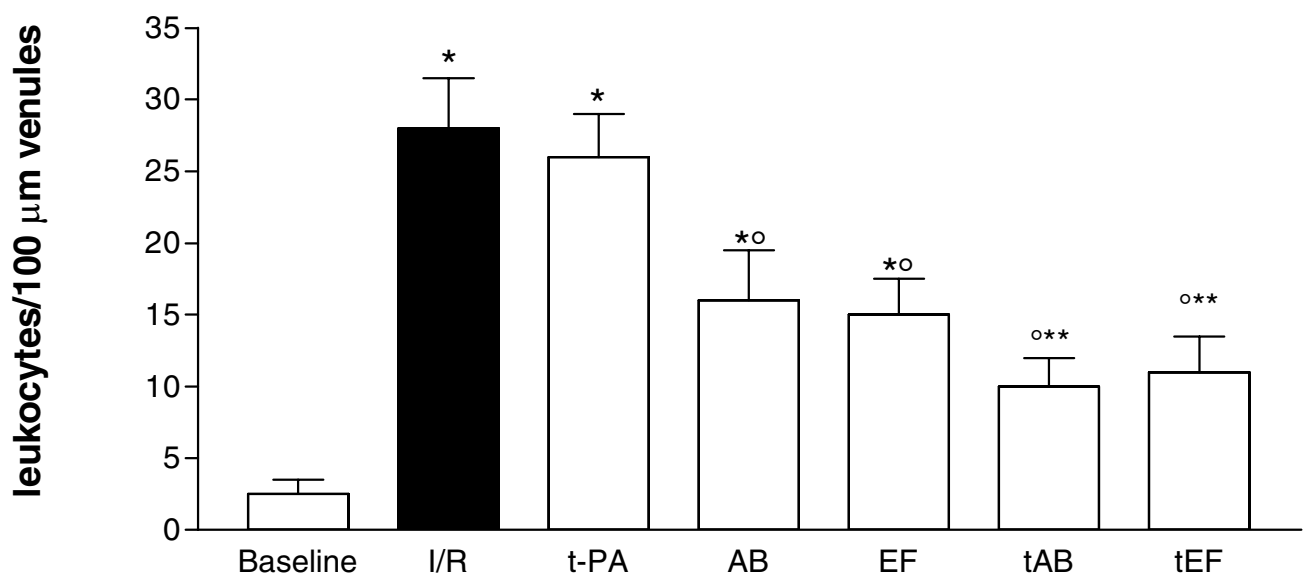

Figure 5

Number of adherent leukocytes/I00 $\mu \mathrm{m}$ venules at baseline and during reperfusion in the group treated with saline (I/R) and those treated with abiciximab ( $A B)$, eptifibatide (EF), t-PA (tPA) and abiciximab plus t-PA (tAB) or eptifibatide plus t-PA (tEF), respectively See text for details. Values are means $\pm S D, n=25$ experimental observations for each entry, ${ }^{*} P<0.001 \quad l / R-t P A$ vs. baseline; ${ }^{\circ} \mathrm{P}<0.05 \mathrm{AB}, \mathrm{EF}, \mathrm{tAB}$, and tEF vs. $\mathrm{I} / \mathrm{R} ;{ }^{* *} \mathrm{P}<0.05 \mathrm{tAB}$ and $\mathrm{tEF}$ vs.AB and $\mathrm{EF}$.

ent platelets, suggesting that the endothelial surface becomes less adhesive with time, possibly because vWF or other factors are progressively washed away [16]. This phenomenon may help to explain the delay of microvascular perfusion and the reocclusion of some microvessels at the end of the period of reperfusion, as observed after treatment with abicixmab or eptifibatide.

Our data show that the protective effects derived from abciximab or eptifibatide after reperfusion are primarily related to inhibition of platelet aggregation while other possibilities contributing to the improvement of I/R injury, may be related to the effect on platelet adhesion and platelet-leukocyte adhesion on the endothelial cells of the venular vessel wall. However, our data showed that the protection with gpIIa/IIIb was not complete thus showing a crucial role for t-PA. Interestingly, gpIIb/IIIa Mabs crossreacts with the leukocyte integrin $\mathrm{Mac}-1$ receptor on activated monocytes and macrophages and blocks adhesion to fibrinogen and ICAM-1 [25], which has also been implicated in the leukocyte recruitment associated with I/R [26].
Our observations might highlight that platelets appear to have a central role in thrombosis in I/R injury suggesting that platelet-dependent processes in I/R injury may significantly affect the fibrinolytic processes. Interestingly, recent data show a greater tendency of fibrinolytic inhibition in sepsis in non-leukopenic patients. Furthermore, in shock conditions, levels of t-PA inhibition were high in both the non-leukopenic and leukopenic groups [27].

In our model of $\mathrm{I} / \mathrm{R}$ it appears that although abiciximab or eptifibatide restored blood flow only abcixmab or eptifibatide in combination with t-PA caused a significant increase in diameter of arterioles and recovered complete microvascular perfusion at the beginning of reperfusion thus indicating that even relatively mild forms of damage may be accompanied by local perfusion deficiencies of the microcirculation and alterations of the endothelial barrier. In agreement with our data in patients treated with eptifibatide, with simultaneous accelerated thrombolyis, it was shown that there was more reperfusion and a shorter duration of ischemia as shown by the shorter time to steady state ST-segment recovery [19]. Campbell et al. pro- 


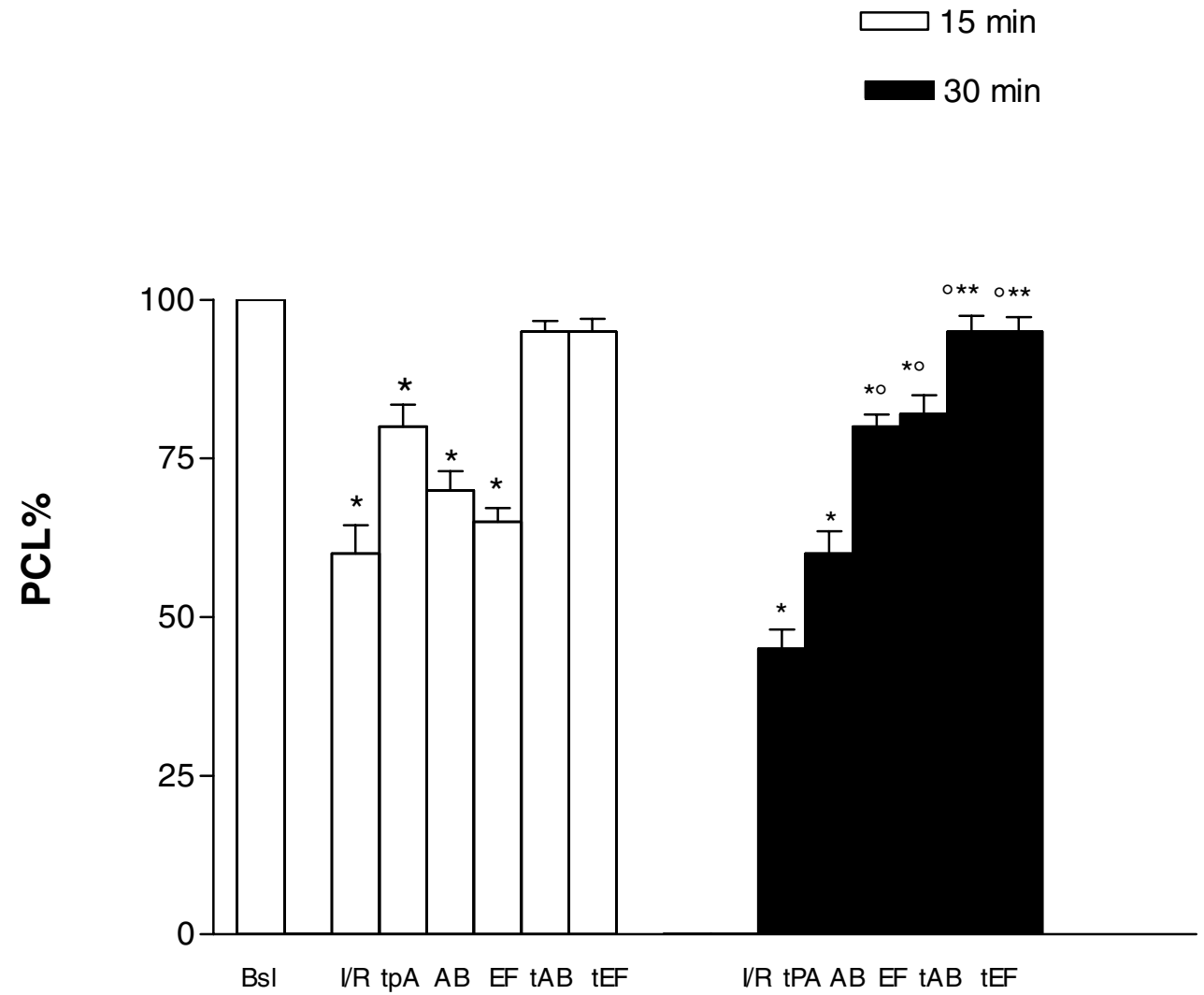

Figure 6

Changes (\%) of perfused capillary length (PCL) at baseline and during reperfusion. in the group treated with saline (I/R) and those treated with t-PA (tPA), abiciximab, $(A B)$, eptifibatide (EF), t-PA and t-PA plus abiciximab (tEF) or eptifibatide (tEF), respectively. See text for details. Values are means $\pm S D ;{ }^{*} p<0.001 \mathrm{I} / \mathrm{R}, \mathrm{tPA}, \mathrm{AB}$, and $E F$ vs. baseline; ${ }^{\circ} \mathrm{P}<0.05 \mathrm{AB}, \mathrm{EF}, \mathrm{t} A \mathrm{~B}$, and tEF vs. I/R and t-PA; ${ }^{* *} \mathrm{P}<0.05$ tAB and tEF vs.AB and $E F$.

vided evidence that abciximab is a potent and effective cardioprotective agent, thus suggesting an inhibition of leukocyte-endothelial cell interactions in order to preserve cardiac contractile function and coronary perfusion in an isolated perfused rat heart model of I/R [28].

t-PA might play a role in maintaining microvascular patency at the beginning of reperfusion by protecting the antithrombogenic characteristics of the vascular endothelium. In ischemia the impairment of endothelial cell integrity might predominate, leading to impaired synthesis and/or the release of endothelial substances such as t-PA. Plasma t-PA is more strictly dependent on endothelial cell function and a better indicator of endothelial viability. Furthermore, the protection afforded by t-PA against the increase in microvascular permeability might be related to the reduction of $\mathrm{O}_{2}^{--}$due to the protective effects of t-PA on the endothelium [29]. Upon activation and aggregation, platelets generate oxygen radicals that 

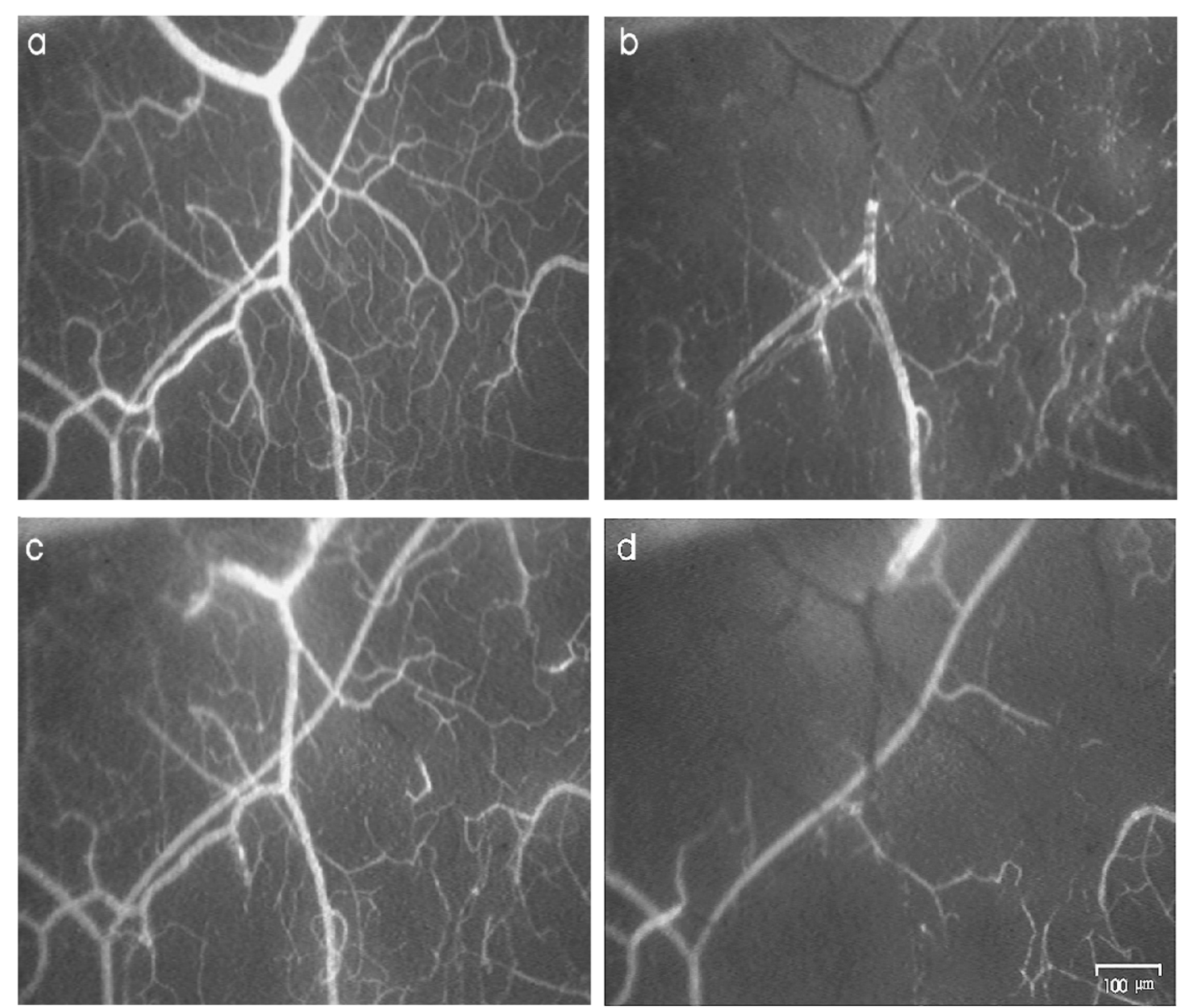

\section{Figure 7}

A sequence of photographs documenting I/R-induced injury in the microcirculation of a control hamster in the baseline condition (a), within $30 \mathrm{~min}$ of ischemia (b), $10 \mathrm{~min}$ (c) and $30 \mathrm{~min}$ (d) of reperfusion. Postischemic microvascular perfusion stopped in many microvessels and blood flow decreased significantly during reperfusion with the evidence of the no-reflow phenomenon.

could cause vasoconstriction and occlusion of the arterioles.

In our model t-PA alone did not exert any protection at 30 min of reperfusion and these results are consistent with data showing that reperfusion treatment by thrombolysis reduces mortality in patients undergoing percutaneous coronary intervention, but its efficacy is limited by the occurrence of thrombotic reocclusion after reperfusion [11], thus suggesting that platelets serve the major role in hemostasis in arterioles during reperfusion in I/R injury. In a first systematic evaluation of eptifibatide combined with low dose t-PA in acute myocardial infarction, Brener et al. showed that this therapy is superior to standard dose t-PA alone in achieving reperfusion of the infarct-related artery $60 \mathrm{~min}$ after initiation of therapy [13].

Recent data show that t-PA inhibits superoxide anion production in human neutrophils in vitro and decreases mortality in patients with acute myocardial infarction [30]. Previously, we showed that leukocytes have a secondary influence on the fibrinolytic system after $30 \mathrm{~min}$ of ischemia and $30 \mathrm{~min}$ of reperfusion while the no reflow phenomenon during $60 \mathrm{~min}$ of ischemia followed by 60 
min of reperfusion appears to be modulated by t-PA in leukopenic hamsters [20]. In agreement with these data, it was shown that the percentage stenosis in the coronary arteries measured by coronary angiography was negatively correlated with t-PA activity that fluctuates because t-PA levels are different according to the ischemic conditions [31].

Therefore, it is possible that the protective effects of t-PA might determine an inhibition of the vasoconstriction and microthrombus formation in arterioles in combination with the inhibitors of platelet aggregation, thus allowing an increase in capillary perfusion. The restoration of blood flow could be essential in the mechanism of protection, thus determining oxygen delivery to the tissue and permitting the extraction of by-products of cellular metabolism during reperfusion. The beneficial effects of tPA might also derive from a more marked reduction of leukocyte and platelet adhesion via the inhibition of oxygen free radical formation.

\section{Study limitations}

Although we have demonstrated a role for platelets in the response to ischemia/reperfusion, there are issues that need to be addressed by future studies. In particular, we do not know the extent of damage to the endothelial cells of the microvessels. For instance, evidence for endothelial barrier swelling or free radical injury to the tissue could be obtained by histological study of the tissue following reperfusion; however, such measurements were beyond the scope of the present study.

\section{Conclusions}

We demonstrated that the inhibition of platelet aggregation is crucial in I/R injury as shown by the treatment with abicixmab or eptifibatide that decreased significantly, not only platelet aggregation in both arterioles and venules, but also leukocyte adhesion in venules in the hamster cheek pouch microcirculation. We have shown that the effects derived from abiciximab or eptifibatide on platelet reactivity involve leukocyte adhesion to endothelial cells of venular vessel walls. However, only the abicixmab or eptifibatide-induced inhibition of platelet aggregation in conjunction with t-PA speeded up the restoration of blood flow. Likewise t-PA decreased the levels of vasoconstriction, abolished the increase in permeability, and increased $\mathrm{RBC}$ velocity in the microvessels, thus indicating that even mild forms of platelet or endothelial cell activation may be accompanied by local perfusion deficiencies of the perfusion and alterations in the properties of the endothelial barrier.

\section{Materials}

Male Syrian hamsters (80-100 g Charles River, Calco, Italy) were used. Hamsters were anesthetized (Nembutal, 5 $\mathrm{mg} / 100 \mathrm{~g}$ body wt., i.p.) and tracheotomized. The right carotid artery and femoral vein were cannulated to measure blood pressure and to administer additional anesthesia and drugs, respectively. Animal handling and care followed the procedures outlined in the Guide for the Care and Use of the Laboratories of the Italian Research Council.

\section{Experimental groups}

In pilot studies we used different doses of abciximab or eptifibatide. Abiciximab was injected i.v. at $6.5 \mu \mathrm{g} / \mathrm{kg}$ and eptifibatide at $6 \mu \mathrm{g} / \mathrm{kg}$ because half dosage caused an increase in permeability and leukocyte adhesion on postcapillary venules. We used six groups: the control (I/R) (n $=5$ ) group received an intravenous infusion of saline; the second group (tPA, $n=5$ ) was treated with t-PA (human rtPA, Sigma Chemical, St. Louis, MO, USA) $(50 \mu \mathrm{g} / 100 \mathrm{~g} /$ $0.7 \mathrm{ml}$ intravenous infusion); the third group $(\mathrm{AB}, \mathrm{n}=5)$ was treated with abiciximab $(0.65 \mu \mathrm{g} / 100 \mathrm{~g}$ infused intravenously); the fourth group ( $\mathrm{EF}, \mathrm{n}=5$ ) was treated with eptifibatide $(0.6 \mu \mathrm{g} / 100 \mathrm{~g}$ infused intravenously); the fifth group ( $\mathrm{tAB}, \mathrm{n}=6$ ) was treated with t-PA plus abciximab (50 plus $0.6 \mu \mathrm{g} / 100 \mathrm{~g}$ intravenous infusion); the sixth group ( $\mathrm{tEF}, \mathrm{n}=6$ ) was treated with t-PA plus eptifibatide ( $50 \mu \mathrm{g}$ plus $0.65 \mu \mathrm{g} / 100 \mathrm{~g} / \mathrm{min}$ infused intravenously). All the drugs were injected 10 mins before ischemia and through 30 mins of reperfusion by using a micropump

The cheek pouch was surgically prepared as previously reported $[4,20]$. The cheek pouch was gently everted and fixed to a special platform on the microscope stage. Then a thin black blade was inserted through a small incision between the upper and lower layers of the pouch. The cheek pouch was superfused with a $36 \pm 0.5{ }^{\circ} \mathrm{C}$ Ringer's solution ( $4 \mathrm{ml} / \mathrm{min}$ ), with $5 \% \mathrm{CO}_{2}$ in $95 \% \mathrm{~N}_{2}$ adjusted to $\mathrm{pH}$ 7.35. Atraumatic microvascular clips were placed on the proximal part of the cheek pouch to achieve complete ischemia for $30 \mathrm{~min}$. The clamp was then removed and the microcirculation was observed for 30 mins during reperfusion.

Observations were made with a fluorescence microscope (Orthoplan, Leica Microsystem GmbH, Wetzlar, Germany) and a filter block (Ploempak, Leica Germany) fitted with a long working distance objective $(\times 4$, na $0.14 ; \times 20$, na 0.25$)$ and $\times 10$ eyepiece. Epi-illumination was provided by a xenon 150-W lamp using the appropriate filters for fluorescein isothiocyanate, bound to dextran (MW 150,000; Sigma Chemical, St. Louis, MO, USA; $50 \mathrm{mg} /$ $100 \mathrm{~g} \mathrm{~b}$. wt., intravenously injected as $5 \% \mathrm{~W} / \mathrm{V}$ solution in $5 \mathrm{~min}$ ), for acridine red and a heat filter. The area of interest was televised with a COHU 5253 SIT (COHU Inc. San Diego CA, USA) low light level camera, and observed on a Sony PVM 122 CE monitor. Video images were videotaped and microvascular measurements were made off- 
line by a computer-assisted imaging software system (MIP Image, CNR, Institute Clin. Physiology, Pisa, Italy).

\section{Measurements of microvascular parameters}

Animals in all the groups received an intravenous injection of acridine red $(1 \mathrm{mg} / 100 \mathrm{~g})$ to visualize the leukocytes and platelets at baseline and after reperfusion. The number of adherent leukocytes was expressed as the number $/ 100 \mu \mathrm{m}$ length of venule (diameters: $16 \pm 8 \mu \mathrm{m}$, length $>250 \mu \mathrm{m}$ ). The number of adherent platelets was expressed as number $/ \mathrm{mm}^{2}$ of vessel surface (diameters: $16 \pm 8 \mu \mathrm{m}$ ). In each animal 5 arterioles and 5 venules were recorded on videotape.
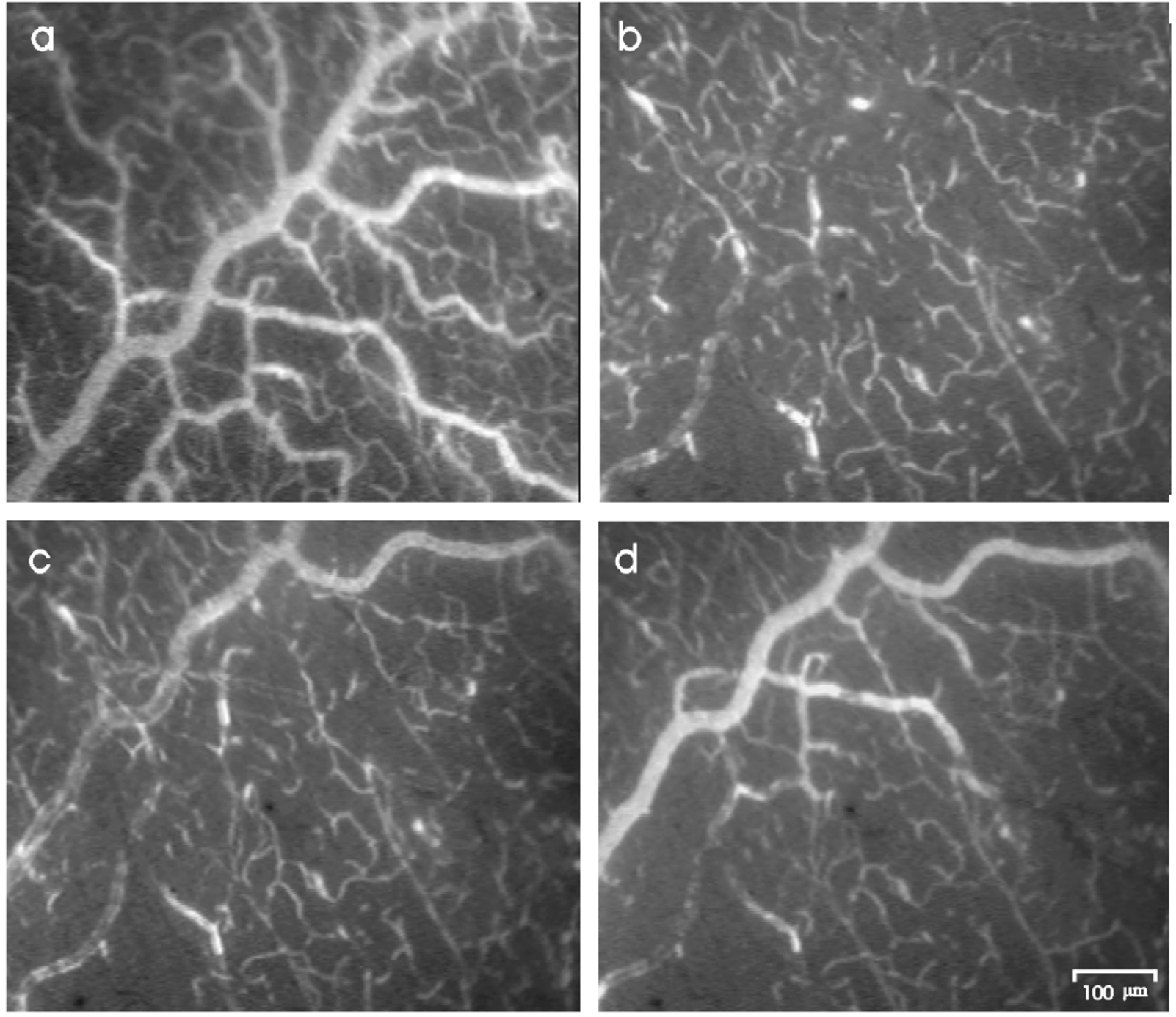

\section{Figure 8}

A sequence of photographs documenting I/R-induced injury in the microcirculation of a hamster treated with abciximab, in the baseline conditions (a), within $30 \mathrm{~min}$ of ischemia (b), $10 \mathrm{~min}$ (c) and $30 \mathrm{~min}$ (d) of reperfusion. Postischemic capillary perfusion increased significantly within 10 or 30 min of reperfusion even if there was not complete recovery.

PCL, defined as the total length of capillary segments that have at least one RBC passing through them in a $30 \mathrm{~s}$ period, was analyzed from four to six different microscopic fields. Microvessel diameters were measured by an image shearing system (Digital Image Shearing Monitor Mod
907, IPM). Red blood cell (RBC) velocity was determined using dual slit cross correlation (velocity tracker Mod 102 B, IPM, San Diego, CA, USA). The measured centerline velocity was corrected according to vessel size to obtain the mean RBC velocity. 
To quantify the permeability of the venular wall, fluorescence intensity in the perivascular space was reported as normalized to baseline grey levels: $N G L=\left(I-I_{r}\right) / I_{r}$, where I is the average baseline grey level and $I_{r}$ is the same parameter after reperfusion [4]. Grey levels, ranging from 0 to 255 , were determined by the MIP Image program. The size of the window used to measure average fluorescence intensity was set at $50 \mu \mathrm{m}$ long and $50 \mu \mathrm{m}$ wide.

Mean arterial blood pressure (MAP) (Viggo-Spectramed P10E2 transducer, Oxnard, CA, USA) and heart rate (HR) were measured by a Gould Windograf recorder (Mod. 136615-10S, Gould Inc., Ohio, USA).

All reported values are means \pm SD. Differences were tested by paired and unpaired t-test. For analysis between groups, the Kruskal-Wallis test was used, followed by the Mann-Whitney U test. Differences were considered significant at $\mathrm{p}<0.05$.

\section{Acknowledgements}

This work was supported by Italfarmaco SpA, Via dei lavoratori, Cinisello Balsamo, Milano, Italy. We thank also Dr. P. Mascagni, Head of the Research Lab. Italfarmaco, for the constructive discussions of this work.

\section{References}

I. Golino, Maroko PR, Carew TE: Efficacy of platelet depletion in counteracting the detrimental effect of acute hypercolesterolemia on infarct size and the no-reflow phenomenon in rabbits undergoing coronary artery occlusion-reperfusion. Circulation 1987, 76:173

2. Massberg S, Enders G, de Melo-Matos FC, LID Tomic, Leiderer R, Eisenmenger S, Messmer K, Krombach F: Fibrinogen deposition at the postischemic vessel wall promotes platelet adhesion during ischemia reperfusion in vivo. Blood 1999, 94:3829

3. Salter W, Krieglstein CF, Issekutz AC, Granger DN: Platelets modulate ischemia reperfusion-induced leukocyte recruitment in the mesenteric circulation. Am J Physiol 200I, 28I:GI 432

4. Bertuglia S, Giusti A, Fedele S, Picano E: Glucose-insulin-potassium treatment in combination with dipyridamole inhibits ischemia-reperfusion-induced damage. Diabetologia 200I, 44:2165-2170

5. Cook NS, Kottirsch G, Zerwes HG: Platelet glycoproteins Ilb/ IIla antagonists. Drugs of the future 1994, 19:135-159

6. The EPIC Investigators: Use of a monoclonal antibody directed against the platelet glycoprotein IIb/Ila receptor in high-risk coronary angioplastly: The EPIC investigation. N Engl J Med 1 994, 330:956

7. Schulman SP, Goldschmidt-Clennont PJ, Topol EJ: Effects of Integrilin a platelet glycoprotein Ilb/lla receptor antagonist in unstable angina, a multicenter trial. Circulation 1996, 94:2083-89

8. Lele M, Stouffer GA, et al: Eptifibatide and 7E3, but not Tirofiban, inhibit $\alpha_{v} \beta_{3}$ Integrin-mediated binding of smooth muscle cells to thrombospondin and prothrombin. Circulation 200I, 104:582-587

9. Foster RH, Wiseman LR: Abciximab. An update review of its use in ischaemic heart disease. Drugs 1998, 56(4):629-665

10. Rote WE, Werns SW, Davis JH, Feigen LP, Kilgore KS, Lucchesi BR: Platelet GPIIb/IIla receptor inhibition by SC-49992 prevents thrombosis and rethrombosis in the canine carotid artery. Cardiovasc Res 1993, 27:500-507

II. Anderson KM, Califf RM, Stone GW, Neumann FJ, Montalesot G, Miller DP, Ferguson JJ, Willerson JT, Topol E): Long-term mortality benefit with Abciximab in patients undergoing percutaneous coronary intervention. JACC 200I, 37:2059-65

12. Lincoff AM, Kereiakes DJ, Mascelli MA, Deckelbaum LI, Barnathan ES, Patel KK, Frederick B, Nakada MT, Topoll El: Abiciximab suppresses the rise in levels of circulating inflammatory markers after percutaneous coronary revascularization. Circulation 200I, 104:163-167

13. Brener SJ, Zeymer U, Adjey J, Vrobel TR, Ellis SG, Neuhaus KL, Juran N, Ivanc TB, Ohman EM, Strony J, Kitt M, Topol E): Eptifibatide and low-dose tissue plasminogen activactor in acute myocardial infarction. JACC 2002, 39:377-86

14. Lele M, Stouffer GA, Sajid M, Wajih N, Stouffer GA: Eptifibatide and 7E3, but not Tirofiban, inhibit $\alpha_{v} \beta_{3}$ Integrilin-mediated binding of smooth muscle cells to thrombospondin and prothrombin. Circulation 200I, 104:582-587

15. Goto S, Sakay H, Goto M, Ono M, Ikeda Y, Handa S, Ruggeri ZM: Enhanced shear rate-induced platelet aggregation in acute myocardial infarction. Circulation 1999, 99:608-II

16. Andre P, Denis CV, Ware J, Saffaripout S, Hynes R, Ruggeri M, Wagner DD: Platelets adhere to and translocate on von Willebrand factor presented by endothelium in stimulated veins. Blood 2000, 96:3322-30

17. Binnema DJ, Dooijewaard G, Turion NC: An analysis of the activators of single-chain urokinase-type plasminogen activator (scu-PA) in the dextran sulphate euglobulin fraction of normal plasma and of plasmas deficient in factor XII and prekaIlikrein. Thromb. Haem I991, 65:144-148

18. Watkins SP, de Lemos JA: Antiplatelet therapy in AMI: Combining GP IIb/IIla inhibition with reduced-dose fibrinolytic therapy. Curr Interv Cardiol Rep 200I, 3:235-43

19. Ohman EM, Kleiman NS, Gacioch G, Worley SJ, Navetta FI, Talley JD, Anderson HV, Ellis S, Cohen G, Spriggs D, Miller M, Kereiakes D, Yakubov S, Kitt MM, Sigmon KM, Califf RM, Krucoff MW, Topol E]: Combined accelerated tissue-plasminogen activator and platelet glycoprotein Ilb/IIla integrin receptor blockade with Integrilin in acute myocardial infarction. Results of a randomized, placebo-controlled, dose-ranging trial. IMPACTAMI Investigators. Circulation 1997, 95:793-80|

20. Bertuglia S, Colantuoni A: Protective effects of leukopenia and tissue plasminogen activator in microvascular ischemiareperfusion injury Am J Physiol 2000, 278: $\mathrm{H} 755-\mathrm{H} 76 \mathrm{I}$

2I. Baldassarre J], Henderson PA, Burns D, Fisher JY: Translocation of protein kinase $C$ isozymes in thrombin stimulated human platelet. Correlation with I,2 dyacylglycerol levels. J Biol Chem 1992, 267:15585-92

22. Rubanyi GM, V PM: Oxygen derived free radicals, endothelium and responsiveness of vascular smooth muscle. Am J Physiol 1986, 250:H8|5-2|

23. Davenpeck KL, Gauthier TW, Lefer AM: Inhibition of endothelialderived nitric oxide promotes P-selectin expression and actions in the rat microcirculation. Gastrenter 1994, 107:1050-8

24. Folts JD, Gallagher K, Rowe GG: Blood flow reductions canine coronary arteries: vasospam or platelet aggregation? Circulation 1982, 65:248-55

25. Simon DU, Xu H, Ortlepp P, Rogers C, Rao NK: 7E3 monoclonal antibody directed against the platelet glycoprotein IIb/IIla cross reacts with the leukocyte integrin Mac-I and blocks adhjesion to fibrinogen and ICAM-I. Arterioscler Thromb Vasc Biol 1997, 17:528-35

26. Kurose I, Anderson DC, MiYasaka M, Tamatani T, Paulson JC, Todd RF, Rusche JR, Granger DN: Molecular determinants of reperfusion-induced leukocyte adhesion and vascular protein leakage. Circul Res 1994, 74:336-42

27. Haj MA, Neilly IJ, Robbie LA, Adey GD, Bennett B B: Influence of white blood cells on the fibrinolytic response to sepsis: studies of septic patients with or without severe leucopenia. $\mathrm{Br} J$ Haematol 1995, 90:54I-7

28. Campbell B, Chuhran CM, Lefer DJ, Lefer AM: Cardioprotective effects of Abciximab (ReoPro) in an isolated perfused rat heart model of ischemia and reperfusion. Methods Find Exp Clin Pharmacol I 999, 2 I (8):529-534

29. Riesenberg K, Sclaeffer K, Katz A, Levy R: Inhibition of superoxide production in human neutrophils by combinations of heparin and thrombolytic agents. $\mathrm{Br}$ Heart J 1998, 73:14-19

30. Lincoff AM, Kereiakes DJ, Mascelli MA, Deckelbaum LI: Abciximab suppresses the rise in levels of circulatory inflammatory markers after percutaneous coronary revascularization. Circulation 200I, 104:163-167

31. Yamada S, Yamada R, Ishii A A, Ashikawa K, Kawamitsu H, Fujita K: Evaluation of tissue plasminogen activator and plasminogen 
activator inhibitor-I levels in acute myocardial infarction. J Cardiol 1996, 27(4): 17|-8

\section{Pre-publication history}

The pre-publication history for this paper can be accessed here:

http://www.biomedcentral.com/1471-2261/2/10/prepub

Publish with BioMed Central and every scientist can read your work free of charge

"BioMedcentral will be the most significant development for disseminating the results of biomedical research in our lifetime." Paul Nurse, Director-General, Imperial Cancer Research Fund

Publish with BMC and your research papers will be:

- available free of charge to the entire biomedical community

- peer reviewed and published immediately upon acceptance

- cited in PubMed and archived on PubMed Central

- yours - you keep the copyright

BioMedcentral.com editorial@biomedcentral.com 